\title{
The Research on Influence Facts of Supply Chain Finance Operation Rui ZHANG
}

\author{
Faculty of management Wuhan University of Technology Wuhan, P. R. China \\ Ix_zr@163.com
}

Keywords: Influence facts, Supply chain finance, Operation.

\begin{abstract}
This paper firstly raised four groups of hypothesis based on previous studies and practices, which are supply chain finance operation level, were influenced by external environment, the overall supply chain finance performance positive affect supply chain finance operation level, the input of financial institute positive affect supply chain operation level, the input from the enterprise on supply chain positive affect supply chain finance operation level, secondly, via investigation, we collected and consolidated influence facts of supply chain finance operation level, thirdly, to do preliminary test based on investigation, and finally selected 19 topics based on preliminary investigation results about reliability and FEA, after parameter estimation and hypothesis test for formal research results, we finally verified fours groups of hypothesis, and in the last part of this paper, we analyzed these four groups of hypothesis.
\end{abstract}

\section{Introduction}

Because there are a lot of participants in supply chain finance and many factors can impact them, which lead to some uncertainty to implement supply chain finance business, If we can tease out the main factors that influence the supply chain financing among the complex influence factors, it will be able to help core enterprise in supply chain finance business operation, This chapter will analysis the influence factors of supply chain financing, first of all, we will raise four groups of research hypotheses according to the theory and experience, then through questionnaire, interview, structural equation model to determine the influence factors of supply chain financing.

\section{Literature review}

Supply chain finance business practice is earlier than the development of theory, Supply chain financing in domestic practice was established in 1999, and after 2000, Supply chain financing along with the practice of the relevant concept of experience gradually formed and slowly mature. In 2002,Lidao, Zhu and others put forward the concept and operation model of finance-transportation; In 2004, Allen Berger, preliminarily discussed the application of supply chain finance framework and ideas; Wang Chan put forward the concept of supply chain finance from the perspective of bank in 2006.Zhou Xiaopeng and Tang Yuanqi Put forward the similar "financial" logistics and supply chain finance concept in 2004.Guo Tao Discussed the principle of accounts receivable financing and financing advantages in 2005.Li Bizhen Illustrated the meaning of finance-transportation and function in 2005. Michael Lamoureux defined the supply chain finance is a core enterprise leading enterprise ecosystem, the availability of funds and the cost of a system optimization process in 2008. Wang Fuqian and Yang Bing Discussed the status and role of commercial Banks in the supply chain financing in 2006. Chu Xuejian discussed the status and role of logistic enterprises in the supply chain financing in 2006.

\section{Determination and analysis for the influential factors in supply chain finance}

Based on the previous literature and investigation, this paper puts forward the supply chain financial main influence factor in below four aspects.

\section{The external environment affects the operation of supply chain financing level}

Supply chain finance business implements under the background of the macro economy, politics, 
technology, culture and other specific environment implementing, which inevitably affected by the external environment, Macroeconomic conditions directly affect the core enterprise's marketing strategy and decision-making such as investment and financing, also can impact the credit allocation and supply chain financing business of core enterprises such as participate in the repo and mortgage. due to the involvement of Banks and other financial institutions, the country's relevant laws and regulations and financial monetary policy will also impact on the supply chain financing business, Supply chain financing belong to financial services, the China banking regulatory commission and other agencies of the bank regulation and financial institutions, Groups such as the China banking regulatory commission also plays an important role on supply chain financing business.

\section{Supply chain performance affects the operation level of supply chain financing}

Supply chain finance is finished under the background of the certain trade between core enterprise and Upstream and downstream small and medium-sized enterprises, therefore, the trade situation between core enterprises and upstream and downstream small and medium-sized enterprises directly influence the operation of supply chain financing, Trade between core enterprise and upstream and downstream $\mathrm{f}$ small and medium-sized enterprises involved in logistics, information flow, cash flow, etc, If the coordination level between core enterprise and upstream and downstream enterprises is high, can promote the core enterprise and upstream and downstream trade stability of small and medium-sized enterprises, which could guarantee the stability of trade between core enterprises and small and middle size enterprise and affect the operation of supply chain financing.

\section{Enterprises on the supply chain affect supply chain financing operation}

One of the key factors for the Implementation of supply chain financing is the credit of core enterprises committed allocate to upstream and downstream enterprises, When the core enterprise's with a strong and comprehensive strength, Banks will grand more credit to them, and the line of credit can be allocated to the financing enterprises will increase as well, meanwhile, the strength of the core enterprise risk prevention ability is one of the factors of if it is willing to participate in of supply chain finance business, When the core enterprise risk prevention ability strong, the motivation to participate in the supply chain finance business will increase, the evaluation and selection from Core enterprise to supply chain financing coordinate members is one of the important part of the core enterprise supply chain financing operation, relatively big sized upstream and downstream enterprises not also is the supporting factors, but also will decide the supply chain financing operation level, the trade relationship between core enterprises and upstream and downstream enterprises is an important measurements for bank to judge if small and middle sized financing enterprise with qualification. So the close relationship of financing enterprises and the core enterprise is an important guarantee for the implementation of supply chain finance business.

The investment level of financial institutions affects the operation of supply chain financing level

The capital source of Small and medium-sized financing enterprises is Banks and other financial institutions, so the attitude of senior management in financial institutions has a larger influence on supply chain financing business structure, at present, SDB which was purchased by Ping An Insurance Co is the earliest bank engaged in supply chain financing, the their investments on supply chain financing business is bigger than the other banks, therefore, the implementation of supply chain financing business is better than the others, the establishment of risk prevention system by SDB is the safe guard to ensure the smoothly implementation of supply chain financing.

\section{Data research}

This research embarks from the research on supply chain financing at home and abroad, and analyze, sort and induce this materials as the foundation of our research. At the same time, based on 
the study of previous literature related, we find entry point of this paper; in general, the empirical research hypothesis and variables design borrowed the research results of scholars at home and abroad to a large extent, In this paper, in the process of designing and modifying the questionnaire, we had many times communication with interviews object to understand their opinions and ideas and they corrected many potential misunderstanding which ensure the scientific, practical and operability of this paper, we did a preliminary test before the formal questionnaire, we collected 98 preliminary test via on-site fill out and email, and finally selected the formal questionnaire effectively based on the Research on the reliability and exploratory factor analysis .

Table 2 Scale of factors on supply chain financing

\begin{tabular}{|c|c|}
\hline Variable & Questions \\
\hline E1 & Good macroeconomic condition when implementing supply chain finance \\
\hline E2 & $\begin{array}{l}\text { Completely related laws and regulations when implementing supply chain } \\
\text { finance }\end{array}$ \\
\hline E3 & $\begin{array}{l}\begin{array}{l}\text { Supply chain finance technology developed when implementing supply chain } \\
\text { finance }\end{array}\end{array}$ \\
\hline E4 & $\begin{array}{c}\text { Electronic and information technology developed when implementing supply } \\
\text { chain finance }\end{array}$ \\
\hline P1 & $\begin{array}{l}\text { High level of coordination of supply chain logistics when implementing } \\
\text { supply chain finance }\end{array}$ \\
\hline $\mathrm{P} 2$ & $\begin{array}{c}\text { High level of coordination in supply chain information flow when } \\
\text { implementing supply chain finance }\end{array}$ \\
\hline P3 & $\begin{array}{c}\text { High level of coordination in supply chain business streams when } \\
\text { implementing supply chain finance }\end{array}$ \\
\hline P4 & $\begin{array}{l}\text { High level of capital flow coordination in supply chain when implementing } \\
\text { supply chain finance }\end{array}$ \\
\hline $\mathrm{C} 1$ & $\begin{array}{c}\text { Strong overall strength of core enterprise when implementing supply chain } \\
\text { finance }\end{array}$ \\
\hline $\mathrm{C} 2$ & $\begin{array}{l}\text { High risk prevention capability of Core enterprise when implementing supply } \\
\text { chain finance }\end{array}$ \\
\hline $\mathrm{C} 3$ & Good prospects of core enterprise when implementing supply chain finance \\
\hline $\mathrm{C} 4$ & $\begin{array}{l}\text { Financing enterprise Trading closely with the core business when } \\
\text { implementing supply chain finance }\end{array}$ \\
\hline F1 & $\begin{array}{l}\text { Senior financial institutions holds a supportive attitude when implementing } \\
\text { supply chain finance }\end{array}$ \\
\hline $\mathrm{F} 2$ & $\begin{array}{l}\text { High degree of application in supply chain finance technology when } \\
\text { implementing supply chain finance }\end{array}$ \\
\hline F3 & $\begin{array}{l}\text { Risk prevention system construction is perfect when implementing supply } \\
\text { chain finance }\end{array}$ \\
\hline F4 & $\begin{array}{l}\text { Organizational structure of commercial banks is perfect when implementing } \\
\text { supply chain finance }\end{array}$ \\
\hline L1 & $\begin{array}{l}\text { A high level of business efficiency in the supply chain when implementing } \\
\text { supply chain finance }\end{array}$ \\
\hline L2 & $\begin{array}{l}\text { A high level of overall supply chain efficiency when implementing supply } \\
\text { chain finance }\end{array}$ \\
\hline L3 & $\begin{array}{l}\text { High levels of supply chain finance for financial institutions, when } \\
\text { implementing supply chain finance }\end{array}$ \\
\hline
\end{tabular}

In this paper, a formal research will use SPSS16.0 statistical analysis software and AMOS structural equation model software 7.0 as the main analytical tools, formal investigation via on-site fill out and email to collect data required for empirical study, and for the study, 198 questionnaires were issued, the last received 186 valid questionnaires in 2 months.

(1)The reliability and validity test

Using SPSS16.0 reliability analysis to analyze the reliability of questionnaire. 
Table 3 Reliability factors on operation level of Supply chain financing

\begin{tabular}{ccc} 
Variable & number of items & Cronbach's $\alpha$ \\
The external environment & 4 & 0.762 \\
Supply chain performance affects the operation & 4 & 0.782 \\
Enterprises on the supply chain & 4 & 0.834 \\
The investment level of financial institutions & 4 & 0.894 \\
The operation level of supply chain financing & 3 & 0.816 \\
\hline
\end{tabular}

(2) Confirmatory factor analysis

With AMOS7.0 software on the formal questionnaire, 186 questionnaires were collected ,five variables, 19 item confirmatory factor analysis, the final result as shown in table 4.

Table 4 Confirmatory factor on influencing factors of Supply chain financing operation level

\begin{tabular}{|c|c|c|c|c|}
\hline & SFL & SR & $\mathrm{CR}$ & AVE \\
\hline & & \multicolumn{3}{|c|}{ The external environment } \\
\hline E1 & 0.680 & 039 & \multirow{4}{*}{0.854} & \multirow{4}{*}{0.522} \\
\hline E2 & 0.732 & 0.36 & & \\
\hline E3 & 0.793 & 0.62 & & \\
\hline E4 & 0.794 & 0.64 & & \\
\hline \multicolumn{5}{|c|}{ Supply chain performance affects the operation } \\
\hline P1 & 0.705 & 0.35 & \multirow{4}{*}{0.856} & \multirow{4}{*}{0.562} \\
\hline P2 & 0.654 & 0.32 & & \\
\hline P3 & .0675 & 0.52 & & \\
\hline $\mathrm{P} 4$ & .0556 & 0.43 & & \\
\hline \multicolumn{5}{|c|}{ Enterprises on the supply chain } \\
\hline $\mathrm{C} 1$ & 0.542 & 0.64 & \multirow{4}{*}{0.784} & \multirow{4}{*}{0.613} \\
\hline $\mathrm{C} 2$ & 0.565 & 0.51 & & \\
\hline C3 & 0.660 & 0.44 & & \\
\hline C4 & 0.678 & 0.31 & & \\
\hline \multicolumn{5}{|c|}{ The investment level of financial institutions } \\
\hline F1 & 0.579 & 0.37 & \multirow{4}{*}{0.783} & \multirow{4}{*}{0.656} \\
\hline $\mathrm{F} 2$ & 0.672 & 0.47 & & \\
\hline F3 & 0.771 & 0.43 & & \\
\hline F4 & 0.873 & 0.64 & & \\
\hline \multicolumn{5}{|c|}{ The operation level of supply chain financing } \\
\hline L1 & 0.529 & 0.37 & \multirow{3}{*}{0.732} & 0.683 \\
\hline L2 & 0.539 & 0.63 & & \\
\hline L3 & 0.679 . & 0.27 & & \\
\hline
\end{tabular}

(2)Parameter estimation and hypothesis testing

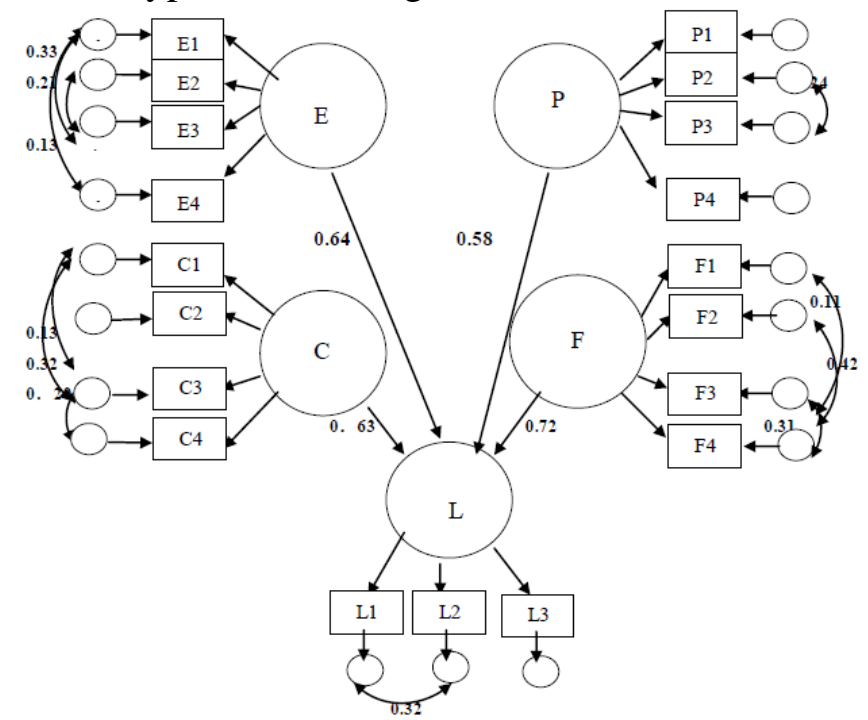

Figure 2 parameter estimation model on factors of Supply chain financing operation level 
Using Amos 7.0 software, the fit the parameters of the model shown in the following table:

Table 5 Model fitting evaluation indicators

\begin{tabular}{|c|c|c|c|c|c|}
\hline$d_{f}$ & $x^{2}$ & $x^{2} / d_{f}$ & P & RMSEA & GFI \\
\hline 452 & 834 & 1.866 & 0.000 & 0.063 & 0.870 \\
\hline PNFI & PGFI & AGFI & NFI & IFI & CFI \\
\hline 0.739 & 0.667 & 0.835 & 0.826 & 0.922 & 0.913 \\
\hline
\end{tabular}

From the fitting indicators, $x^{2} / d_{f}<2 、$ RMSEA $<0.08 、$ AGFI NFI $>0.8$;IFI $、$ CFI $>0.9 . P N F I$ 、 PGFI $>0.5$.Therefore, from the whole, a better model fit the parameters of the model can be accepted.

Inspection standards established in this study assumed that the relationship is: path coefficients greater than 0.5 , the significance level of 0.05 or more is considered a positive correlation between variables; through structural equation modeling path coefficient estimates found four sets of relationships established, so

H1: The external environment positively affects the supply chain financing operation level

$\mathrm{H} 2$ : overall supply chain performance positively affects the supply chain financing operation level

H3: the investment level of enterprises on supply chain positive affects the supply chain financing operation level

H4: Financial institutions positive affect the operation of supply chain financing level

\section{Conclusion}

Because many parties involved in supply chain financing operation, and involved in finance industry which direct supervised by national government, which leads to complex influence factors for its operation level, In this paper, based on literature review, clarify the influence factors of supply chain financing operation level. Environment positively affects the supply chain financing operation level; the final credit provider in supply chain finance is the bank, which involves the bank loan interest rates, credit lines and a series of factors, these factors will inevitably be affected by the country's macroeconomic policy, overall supply chain performance positively affects the supply chain financing operation level, the trade relationship between core enterprises and upstream and downstream enterprises is an important measurements for bank to judge if small and middle sized financing enterprise with qualification. When information, capital, business between the supply chain coordination is good, the bank will increase the confidence of the credit, the investment level of enterprises on supply chain positive affects the supply chain financing operation level, smoothly implementation of supply chain financing depends on the strength of the core enterprise, When the core enterprise investment level is higher, the whole supply chain level and competitiveness will improve as well, Supply chain financing risk management, and supply chain finance business implementation level is one of the key factors decide whether the financial institutions involved in the supply chain financing operation or not, When financial institutions investment level is high, the business with strong risk control and advanced technology will drive supply chain financing to a higher level.

\section{References}

[1] Jason Busch.Live Dispatch:Ariva and Orbian Partner to Take on the Banks[J],Spend Matters,2006,144-167.

[2] Demica.Steady Supply, The growing role of Supply Chain Finance in a changing world[J],Demica Report Seris,January,2007,213-232.

[3] Demica.Demand and Supply: Supply chain finance [J], Demica Report Seris, May, 2008, 178-189. 